\title{
CONGENITAL STRIDOR CAUSED BY AN ABERRANT PULMONARY ARTERY
}

\author{
BY \\ T. M. WELSH and I. B. MUNRO \\ From the Thoracic Surgical Unit, Mearnskirk Hospital, Glasgow, and Ruchill Hospital, Glasgow
}

(RECEIVED FOR PUBLICATION NOVEMBER 3, 1953)

That congenital stridor can be caused by vascular abnormalities has become more widely known during the past few years. With this increased awareness, the list of anomalies known to be capable of causing respiratory embarrassment has lengthened. The following case is, as far as we are aware, the first one due to an aberrant pulmonary artery to be described.

\section{Case Report}

The patient was a boy, the youngest of three children, the others having had no relevant illnesses. He was delivered normally at term. During the first two weeks after birth he had been well, but then developed a wheeziness which was constantly present although varying in intensity. This variation bore no relation to feeding, and he did not regurgitate his feeds. He was admitted to another hospital at the age of 4 months with an acute respiratory infection diagnosed as tracheo-bronchitis. This resolved within a week, but the child remained wheezy.

At the age of 5 months he was admitted to Ruchill Hospital having developed another attack of acute respiratory distress during the preceding 24 hours. There was marked stridor with indrawing of the lower intercostal spaces and supraclavicular fossae. Expiratory wheezing was more marked than inspiratory. Percussion of the chest was normal. On auscultation, coarse crepitations were heard throughout both lungs. The lungs were clear radiologically. Acute tracheo-bronchitis was diagnosed. $\mathrm{He}$ was placed in a steam tent and treatment with aureomycin, $50 \mathrm{mg}$. every six hours, was begun. The temperature, which had been $101 \cdot 2^{\circ} \mathrm{F}$. on admission, was normal within 24 hours, and the child's condition was sufficiently improved within 48 hours for him to be removed from the steam tent. On the sixth day aureomycin was discontinued. The child by then was fairly lively. He had shown no reluctance to feed, and no exacerbation of his symptoms was associated with feeding. Wheeziness, however, remained but was now confined to expiration. During sleep it was almost inaudible.

The history was, of course, suggestive of an anomaly of the great vessels causing compression of the trachea. When the child was sufficiently well, investigations were begun. Laryngoscopy was normal. No narrowing of the trachea could be seen radiologically on the posteroanterior and lateral views of the chest, but the trachea was not outlined with iodized oil for fear of precipitating a further acute respiratory infection. Unfortunately, as the child would not cooperate, it was difficult to get satisfactory radiographs of the barium-outlined oesophagus. The films obtained excluded gross compression or deviation but were not of sufficient quality to show minor indentations. Further examination was about to be made but was prevented by the child's developing a recurrence of the illness which had originally led to his admission. He was then 6 months old. He was seen by Mr. R. S. Barclay and transferred to the Thoracic Surgical Unit at Mearnskirk Hospital. The diagnosis of a vascular anomaly had not yet been established but the

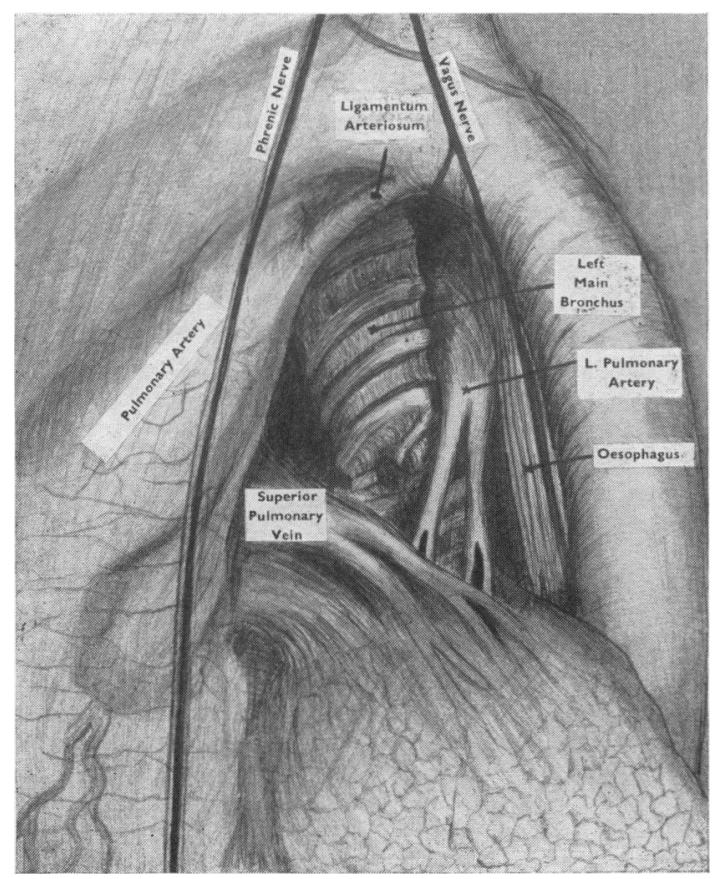

FIG. 1.-Drawing showing the appearances of the left hilum at operation. 


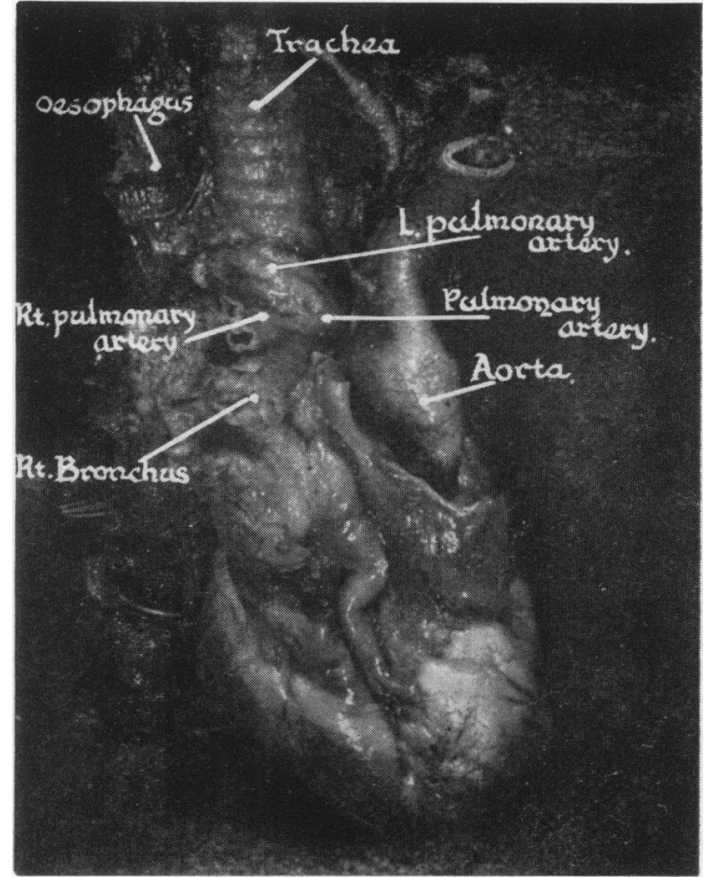

FIG. 2.-Right lateral view of the dissected necropsy specimen. It shows the main pulmonary artery passing to the right of the trachea. The right branch is given off and lies above the right main bronchus. The left branch then passes between the trachea and the oesophagus.

respiratory embarrassment was so great that immediate thoracotomy was considered imperative.

A left thoracotomy was performed. The lung was retracted downwards to expose an apparently normal aortic arch. The mediastinal pleura was incised above the aortic arch to permit the index finger to burrow through to the lower end of the trachea. A cord-like structure could be felt traversing the posterior wall of the trachea, but its identification was delayed until the aortic archway had been dissected out and the structures of the lung hilum exposed. The beginning of the left pulmonary artery was not located in its usual situation. Instead, the upper lobe arterial branches were followed upwards to find the parent vessel lying in the groove between the bronchus and the oesophagus. At this stage the anomaly became obvious. It is illustrated in the drawing (Fig. 1) and in the photographs of the dissected necropsy specimen (Figs. 2 and 3). The main pulmonary artery was unusually long and passed to the right of the trachea where the right pulmonary artery was given off. The left branch passed between the trachea and the oesophagus to gain the left hilum. It was firmly adherent to the trachea which was considerably constricted at this point. The remainder of the ring was made up of the ligamentum arteriosum, and pleural, neural and lymphatic tissue connecting the lung root to the pericardium.

Any attempt at correcting the fault was forestalled by the onset of cardiac arrest which, in spite of cardiac massage, proved irreversible.

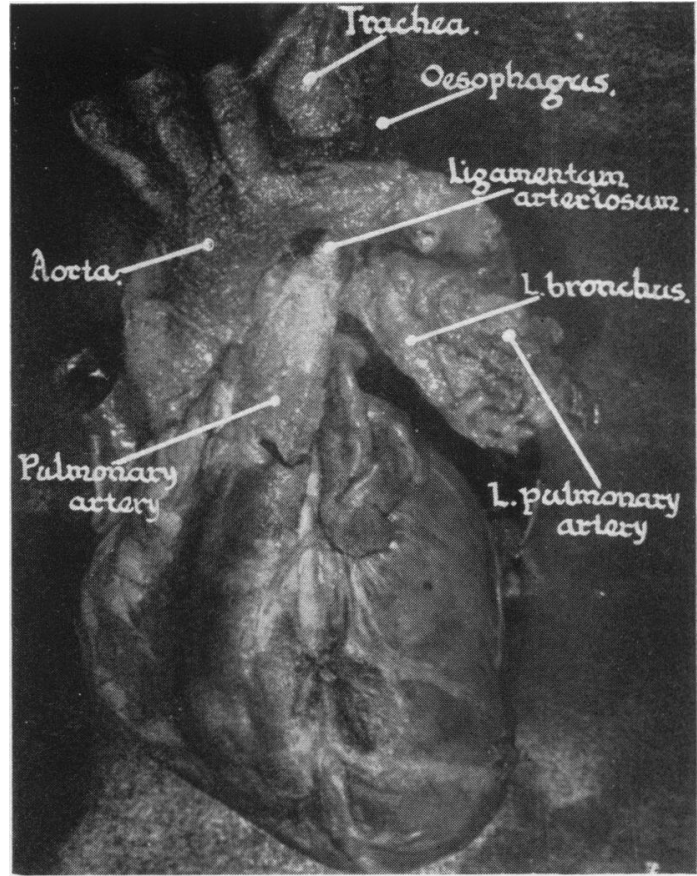

FIG. 3.-The same, left anterior oblique view. The left pulmonary artery has emerged from between the oesophagus and the trachea and occupies its normal position at the hilum of the left lung.

\section{Discussion}

We do not intend setting out a detailed description of the vascular anomalies which cause stridor. The reader is referred to recent articles by Apley (1949), Gross and Neuhauser (1951) and Dolton and Jones (1952).

The history of the case described above is common to many of these abnormalities but there are some features which are worthy of comment. In the first place, the negative result of the investigations makes any remarks in this connexion speculative. Nevertheless, bearing in mind the appearance of the anomalous vessel at operation and necropsy, it seems probable that satisfactory films of the bariumoutlined oesophagus would have shown an indentation in this region. Even more certainly radiographs of the trachea outlined with iodized oil would have shown narrowing. Opinion on the danger of this procedure varies. Most writers think it harmless, but Dolton and Jones (1952) and Smithells (1953) view it with disfavour because of the liability of these cases to respiratory infection.

A further method of investigation, angiocardiography, was not available.

The position in the respiratory cycle of the wheezing is of some interest. All accounts of vascular 
anomalies, if they mention the phase in which stridor occurs, state that it is during inspiration. In the case we have described it was chiefly expiratory during the acute episodes and wholly so in the intervals between. This may be related to the change in arterial pressure during respiration.

Finally, a few remarks on the operation are indicated. Good pulmonary ventilation was maintained throughout, and it seems probable that death was attributable to sustained traction on the left lung, causing complete obliteration of the left pulmonary artery, and, by angulating the origin of the right pulmonary artery, reducing the circulation to the right lung.
Had death not occurred at that juncture, relief of the constriction might have been effected by division of the left pulmonary artery, either alone or with reanastomosis in front of the trachea, or with implantation of the distal end into the main pulmonary trunk, or by division of the ligamentum arteriosum with the object of allowing the main pulmonary artery to move to the right.

This case was under the care of Dr. J. H. Lawson and Mr. R. S. Barclay, to whom we are grateful for permission to publish.

\section{REFERENCES}

Apley, J. (1949). Proc. roy. Soc. Med., 42, 918

Dolton, E. G. and Jones, H. E. (1952) Lancet, 1, 537.

Gross, R. E. and Neuhauser, E. B. D. (1951). Pediatrics, 7, 69.

Smithells, R. W. (1953). Archives of Disease in Childhood, 28, 204. 